\section{JOINT STRENGTH OF MIXED SILYL MODIFIED POLYMER-EPOXY ADHESIVE ON SINGLE LAP JOINT ETCHED ALUMINUM}

\author{
Sri Hastutia, Neng Sri Suhartyb, Triyonoa*
}

aMechanical Engineering Department, Universitas Sebelas Maret, Surakarta, Indonesia bDepartment of Chemistry, Universitas Sebelas Maret, Surakarta, Indonesia
Article history

Received

19 September 2016

Received in revised form

3 November 2016

Accepted

15 July 2017

*Corresponding author triyonomesin@uns.ac.id

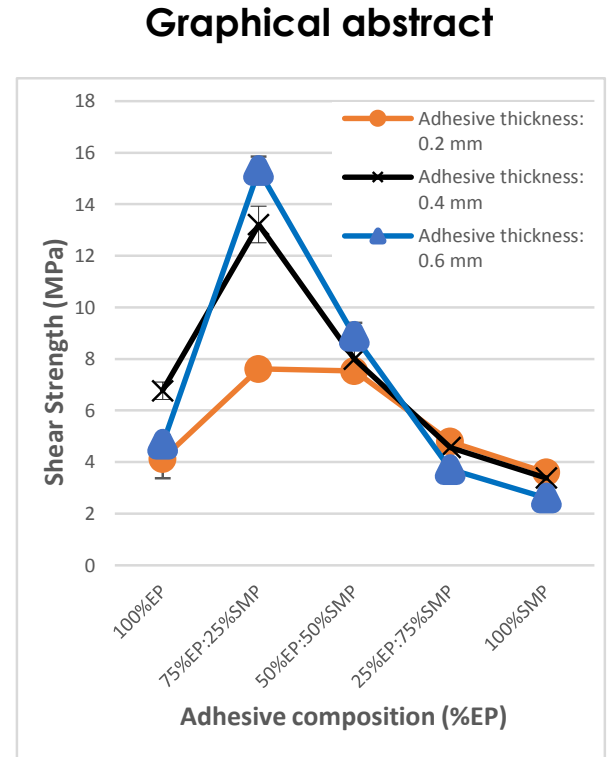

\begin{abstract}
Currently, aluminum alloy is widely used in an automotive structure such as bus body materials due to decreasing the structure weight and fuel consumption. In this structure, there are tens or even hundreds of joints to meet the engineering design. Because of its advantages, the adhesive joint is usually chosen. Aluminum is stiff enough, but it can deform easily. Due to its deformability, cracks will occur easily on the aluminum adhesive joint if it is joined using strong and stiff adhesive. Otherwise, it will be very weak if it is joined using flexible adhesive. The mixture of the strong adhesive, epoxy (EP) and the ductile adhesive, silyl modified polymer (SMP) was proposed for joining aluminum. This study aims to evaluate the effect of the composition of mixed adhesive and its thickness on the strength of single lap joint (SLJ) etched aluminum. Before joining process, the aluminum surface was treated by sandpapering (SDP), and then chromicsulphuric acid (CSA) etch. The composition variations of mixed adhesive were 100\%EP, 75\%SMP:25\%EP, 50\%SMP:50\%EP, 25\%SMP:75\%EP, and 100\%SMP. Mixed adhesives were prepared by using a stirrer with a spatula for 4-6 minutes at 60 rpm. SLJ specimens were manufactured through bonding of two aluminum sheets surface with an adhesive and giving $0.1 \mathrm{MPa}$ pressure. The thickness adhesive was varied of $0.2 \mathrm{~mm}, 0.4 \mathrm{~mm}$, and $0.6 \mathrm{~mm}$. Specimens got a postcuring process at $100^{\circ} \mathrm{C}$ for 100 minutes. The shear tests were performed to evaluate the strength of SLJ. The experimental result showed that the surface treatments of SDP and CSA give higher porosity on the adherend surface. The highest strength and elasticity modulus were achieved by joint of $25 \%$ SMP:75\%EP mixed adhesive joints. The addition a few of SMP adhesive in EP adhesive and adherend surface treatment increases the joint strength. All of the joints have mixed failure mode except the $100 \%$ EP adhesive joint has an adhesive failure mode.
\end{abstract}

Keywords: Mixed adhesive, silyl modified polymer, epoxy, aluminum, single lap joint

(C) 2017 Penerbit UTM Press. All rights reserved

\subsection{INTRODUCTION}

The joining technology has been widely used especially in transportation industry nowadays, such as automotive, railway, aerospace, and naval industries [1-2]. Rivet, welding, and adhesive are some kinds of joining methods. The adhesive joint has advantages such as low manufacturing cost, simple joint, 
environmental resistance, and without machining processes [3-5]. There are many configurations of the adhesive joint. The most popular is a single lap joint (SLJ) [3]. The adhesive joint can be used in similar materials or dissimilar materials like metal to metal, composite to composite, and metal to composite [5].

Two types of adhesive materials, strong and weak adhesive were well known in adhesive engineering. The strong adhesive has high strength and stiffness, but it is brittle. Epoxy is the example of strong adhesive. It is thermoset polymer and widely used due to the good properties such as chemical resistance and low cost [6]. However, due to its brittleness, its scope of use as the adhesive is limited [7]. It is not appropriate for joining the low stiffness materials because it will crack easily when the joined material is deformed., Post-curing treatment is usually performed To improve the properties of epoxy [8]. In reverse, the weak adhesive has low strength and stiffness, but it is very ductile. Silyl-modified polymer (SMP) is the example of weak adhesive. SMP adhesive has advantages such as solvent-free and PVC-free, very good resistance to UV, odorless, fast curing and permanent elastic at a temperature range from $-40^{\circ} \mathrm{C}$ to $120^{\circ} \mathrm{C}$. SMP adhesive used in construction bonding metal or non-metal joint and seal on buses, trains, and trucks.

Previous studies showed that there are many methods to improve the strength of adhesive joints. Some of them are as follows; the filler addition in the adhesive with specific percent $[9,10,11]$, the mixing of strong-brittle and the weak-ductile adhesives [12, 13, 14] and the adherend surface treatment [5, 14, 15]. The addition of filler in the adhesive material can increase the strength and stiffness of the adhesive material. The mixed adhesive joints provide an advantage whereby the joint becomes stronger than the joint using only brittle adhesive or ductile adhesive alone. The surface treatment is usually conducted for coarsening and etching so that bonding between adherend and adhesive can occur and increase the strength and durability.

Aluminum alloy has advantages, such as good strength, good corrosion resistance, good formability and good weldability [16]. Based on these properties, it is widely used in engineering application. In the application, aluminum sometimes must be joined to meet the engineering design requirement. For example, nowadays, structures of bus body use an aluminum alloy to decrease the structure weight and fuel consumption. In this structure, there are tens or even hundreds of joints. The adhesive joint is usually chosen due to its advantages. It is well known that aluminum has a lower stiffness than steel but higher stiffness than polymer matrix composite. It means that the aluminum is stiff enough, but it can deform easily. Due to its deformability, cracks will occur easily on the aluminum adhesive joint if it is joined using strong and stiff adhesive. Otherwise, it will be very weak if it is joined using flexible adhesive. Accordingly, enhancement of adhesive joint strength between aluminum to aluminum is important to be investigated due to the limitation of adhesive joint data.

Moreover, aluminum will react with oxygen to form a thin layer of alumina on the surface of the material. This layer has no pores so that the aluminum surface becomes very smooth. Previous studies [17-21] noticed the importance of surface and its positive influence on the bond strength. There are many surface treatments to aluminum alloy sheets in the adhesive single lap joint such as caustic etch (CE), tucker's reagent (TR), sodium dichromate-sulphuric acid (CSA) etch, abrasive polishing (AP), and solvent wiping (SW). The CSA etch treatment increases the failure load of adhesive joint by about $18 \%$ [5]. Surface treatment preparation of adherends aluminum with chemical pre-treatment acid etching makes higher porosity of the oxide layer formed [22]. Another study showed that the chemical treatment on adherend surface give the result the specimens to achieve a higher joint strength, but the chemically treated specimens are not sensitive to the presence of surface pattern [1]. Fractures surface of chemically treated specimens have a cohesive failure mode. Surface pattern of adherend can be generated by mechanically surface pattern using a milling machine. Mechanically surface pattern with a depth of $0.1 \mathrm{~mm}$ can improve the adhesive joint strength of aluminum joint [9].

Based on previous studies, this study will evaluate the mixed adhesive joint between aluminum and aluminum. Two types of adhesives, very stiff-brittle epoxy and more flexible-ductile silyl modified polymer (SMP) adhesives were mixed in variations of composition adhesive. The composition of mixed adhesive which generates the strongest joint will be determined as the best composition. The adherend surface was given chemical treatment using chromic acid etch. Shear test and fracture surface investigation were performed to evaluate the best composition of adhesives which achieve the highest shear strength.

\subsection{METHODOLOGY}

Adhesive materials used silyl modified polymer (SMP) and epoxy (EP) resin. SMP adhesive used Simson ISR 7005 produced by Bostik Inc., Netherlands. Epoxy (EP) adhesive used epoxy resin epichlorohydrin type of bisphenol-A (DGEBA) and hardener used type Polyaminoamide (PAA). Adherend materials used aluminum alloy sheets series 5083. Aluminum sheets were cut according to standard ASTM D1002.

Etching treatments were used for cleaning the surface of aluminum alloy sheets before the joining process. Based on the previous study, the aluminum surface was made rougher using sandpapering of \# 150 [23]. Degrease was dipping in the trichloroethylene solution (30 minutes) and then washing with water. 
Degrease was also dipping in the isopropyl alcohol solution (30 minutes). The etching process was conducted by immersing the aluminum adherend in chromic-sulphuric acid (CSA) solution. It consisted of $\mathrm{H} 2 \mathrm{SO} 4$ solution $(22,5 \mathrm{~g})$, sodium dichromate $(7,5 \mathrm{~g})$ and distilled water $(70 \mathrm{~g})$. Immersing process was performed for 2 - 4 hours [9] and adherend then be washed using distilled water. Etched adherend materials were then dried by using a tissue and kept in the air-tight room until use.

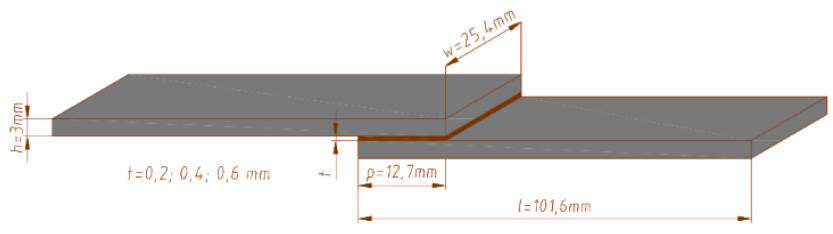

Figure 1 Single lap joint specimen (ASTM D1002)

Tabel 1 Research parameters

\begin{tabular}{ccc}
\hline No. & Adhesive composition & $\begin{array}{c}\text { Adhesive thickness } \\
(\mathbf{m m})\end{array}$ \\
\hline 1 & & 0.2 \\
2 & $100 \%$ EP & 0.4 \\
3 & & 0.6 \\
\hline 4 & & 0.2 \\
5 & $75 \%$ SMP:25\%EP & 0.4 \\
6 & & 0.6 \\
\hline 7 & & 0.2 \\
8 & $50 \% S M P: 50 \% E P$ & 0.4 \\
9 & & 0.6 \\
\hline 10 & & 0.2 \\
11 & $25 \% S M P: 75 \% E P$ & 0.4 \\
12 & & 0.6 \\
\hline 13 & & 0.2 \\
14 & $100 \% S M P$ & 0.4 \\
15 & & 0.6 \\
\hline
\end{tabular}

Two types of adhesives, Silyl Modified Polymer (SMP) and Epoxy (EP) were used in this study. The thickness adhesive was varied of $0.2 \mathrm{~mm}, 0.4 \mathrm{~mm}$, and $0.6 \mathrm{~mm}$. Variations of mixed adhesive composition were $100 \%$ EP, 75\%SMP:25\%EP, 50\%SMP:50\%EP, 25\%SMP:75\%EP, and $100 \%$ SMP in weight fraction. The research parameters are resumed in Table 1. Mixed adhesives were prepared by using a stirrer with a spatula for 4-6 minutes at $60 \mathrm{rpm}$. SLJ specimens were manufactured through bonding of two aluminum sheets surface with an adhesive and giving 0.1 MPa pressure. Specimens got a post-curing process at $100^{\circ} \mathrm{C}$ for 100 minutes.

The procedures of adhesive joints were done based on the standard of ASTM D1002. The configuration of joint specimens was shown in Figure 1 with the symmetry overlap. The single lap joint test used single lap shear test using a JTM UTS-210. Joint strength SLJ can be calculated by equation (1). The fracture surface was observed by using both Scanning Electron Microscope (SEM) and optical microscope. The magnification of SEM and optical microscope were 1,000x and 200x respectively.

$$
\text { Joint strength }=\frac{\text { maximum load }}{\text { adhesived area }}
$$

\subsection{RESULTS AND DISCUSSION}

The etching treatment successfully made the aluminum surface rough due to appear the porosity on the adherend surface after CSA treatment as seen in Figure 2 (a). It gives some benefits as producing stronger adhesive joint strength, increasing contact area joint, producing intrinsic adhesion, providing some degree of mechanical interlocking and keying between adherend with adhesive [22, 24]. The EDS spectra in Figure 2(b) shows that the content of Aluminum is 91.6 At\%, while that of Oxygen is $8.4 \mathrm{At \%}$. It indicated that the adherend surface is free from greases and other organic contaminants. The chemical treatment on the aluminum surface is based on the corrosion process from the acid environment. The acid solution dissolves the natural oxide layer, cleans and activates the aluminum surface, and then generates a new porous of the oxide layer of the aluminum surface [22].
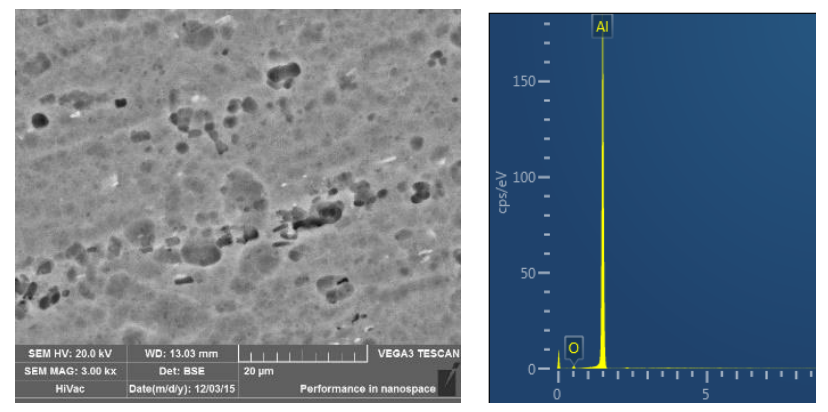

Figure 2 (a) The SEM image of the CSA etched surface adherend and (b) Energy Dispersive Spectrometer (EDS) of the bulk adherend surface

Adhesive joint strength based on the variations of the adhesive thickness and adhesive composition is presented in Figure 3. The addition of few SMP in epoxy adhesive increased the joint strength in the single lap joint aluminum to aluminum. The improvement of joint strength appeared on the mixed adhesive joint with the composition of $25 \%$ EP:75\%SMP. Its strength is $15.32 \mathrm{MPa}$ at an adhesive thickness of $0.6 \mathrm{~mm}$. It is the highest strength comparing to all specimens both mixed adhesive joints and individual adhesive joints. The addition a few percents of SMP (Up to 25\%) in EP adhesive can increase the adhesive joint strength significantly. In this composition, the mixed adhesive was still strong enough due to the high content of EP, but it can attach to adherend surface strongly due to the presence of SMP. EP has a role in maintaining the cohesive force because of its strength and stiffness while SMP has a role in maintaining the adhesive force between adhesive materials and the adherend. Based on these roles, the thicker the adhesive, the stronger the joint. 
Presence SMP in EP adhesive in the range from $25 \%$ to $75 \%$ decreased the joint strength although its strength was still higher than the strength of EP adhesive joint individually. In this composition, the presence SMP in EP adhesive weakened the adhesive materials. Figure 3 also shows that in this composition, the adhesive thickness did not affect the joint strength significantly. The 100\% SMP adhesive joint had the lowest strength due to the nature of SMP adhesive. Silyl Modified Polymer (SMP) adhesive has low strength and stiffness [14]

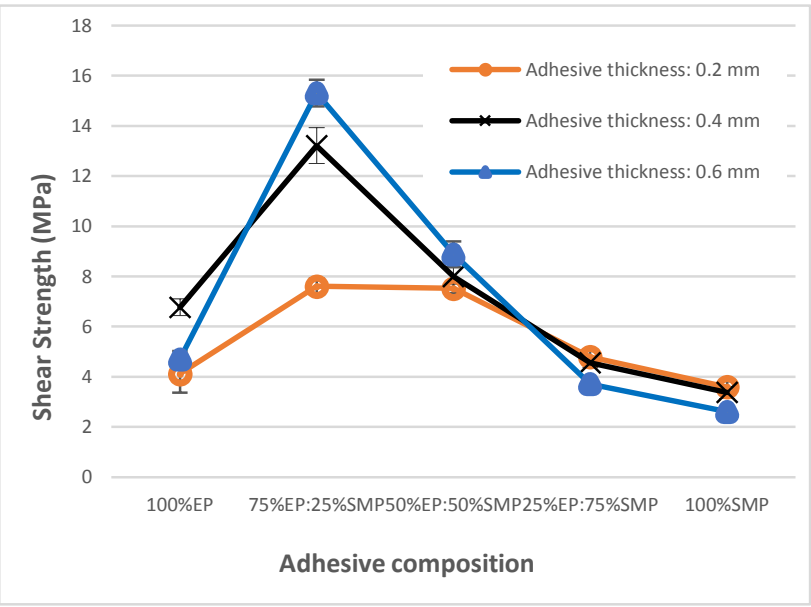

Figure $\mathbf{3}$ Shear strength of the mixed adhesive joint

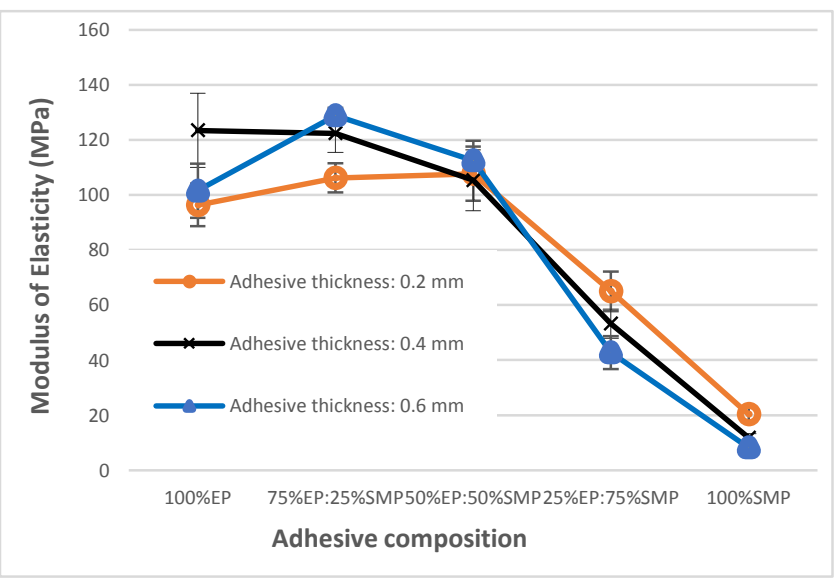

Figure 4 Elasticity modulus of the mixed adhesive joint

The modulus elasticity and elongation of the mixed adhesive joint based on the variation of the mixed adhesive composition for all levels of thickness are shown in Figure 4 and Figure 5 respectively. As previously predicted based on the nature of EP and SMP, the 100\%EP adhesive joints had a higher modulus elasticity than 100\%SMP adhesive joints, but the elongation of the 100\%EP adhesive joints was lower than that of the 100\%SMP adhesive joints. This fact appropriates to the previous research results which stated that the EP adhesive joint is stiff and strong while the SMP adhesive joint is weak and ductile [14, 25]. The interesting point in the current research is the addition of SMP in EP adhesive up to $50 \%$ did not affect the stiffness and brittleness of EP adhesive but affected the strength of the adhesive joint. Elasticity modulus and elongation tend to be constant in this range of addition SMP adhesive in EP adhesive while the strength increases significantly especially at mixed adhesive of 75\%EP:25\%SMP. This case showed that mixed adhesive between EP and a few SMP could enhance adhesive characteristic without losing the fracture toughness. It means that the mixed adhesive between EP and a few SMP meet the requirements of good adhesive as stated by Prolongo et al. [26].

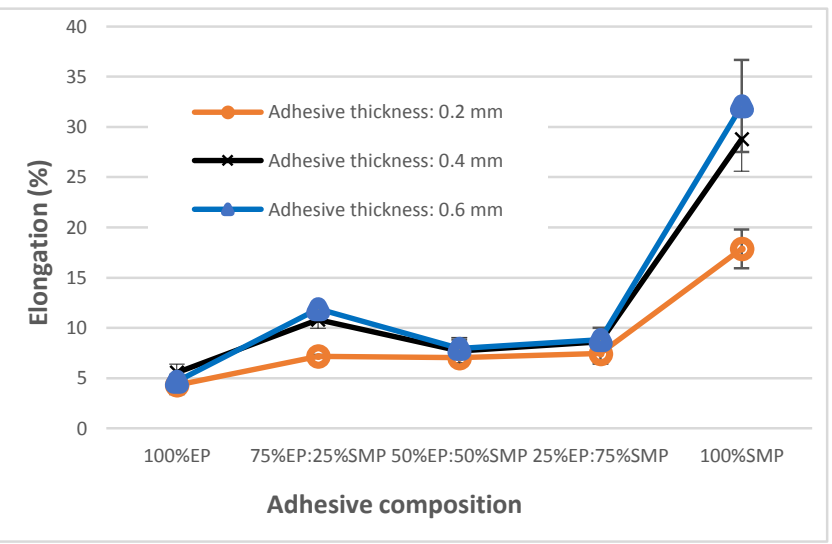

Figure 5 Elongation of the mixed adhesive joint

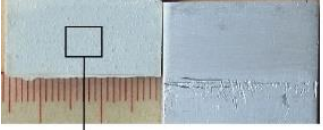

(a)

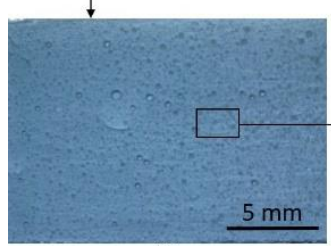

(b)

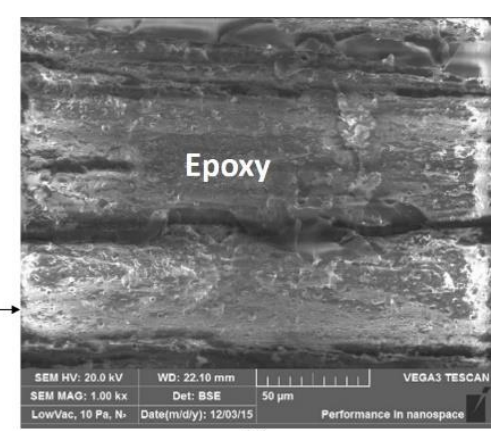

(c)
Figure 6 Fracture surface of 100\% EP joint; (a) complete view, (b) macro view, (c) micro view

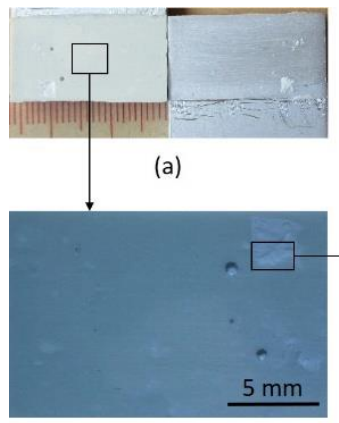

(b)

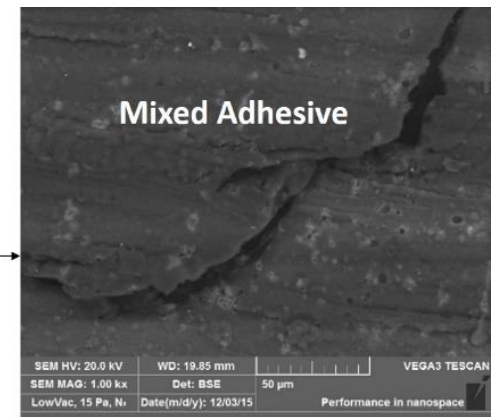

(c)
Figure 7 Fracture surface of 75\%EP:25\%SMP joint; (a) complete view, (b) macro view, (c) micro view 


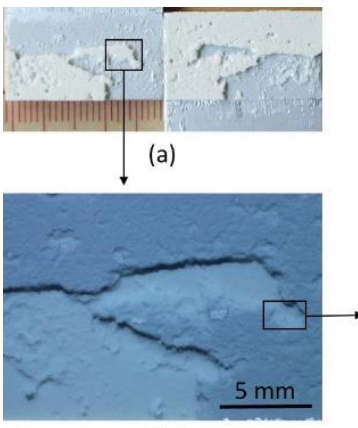

(b)

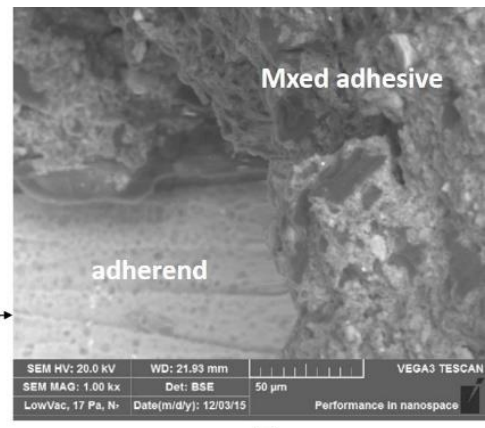

(c)
Figure 8 Fracture surface of 50\%EP:50\%SMP joints; (a) complete view, (b) macro view, (c) micro view

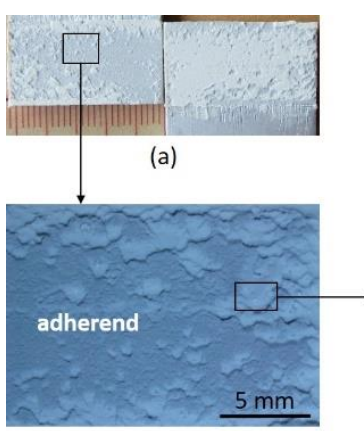

(b)

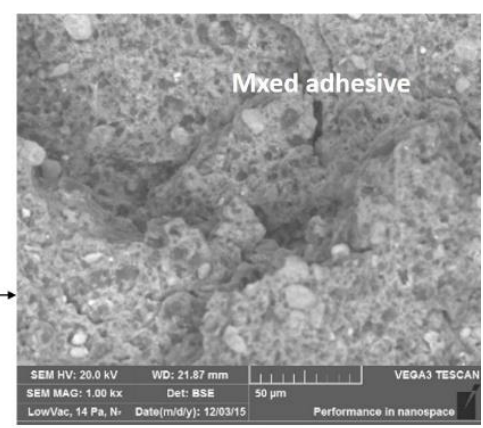

(c)
Figure 9 Fracture surface of 25\%EP:75\%SMP joints; (a) complete view, (b) macro view, (c) micro view

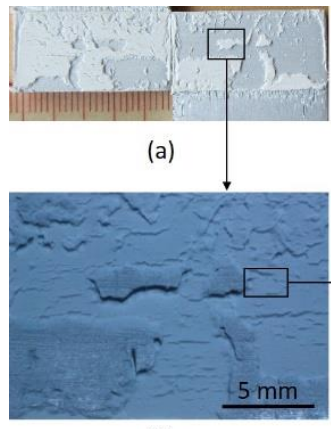

(b)

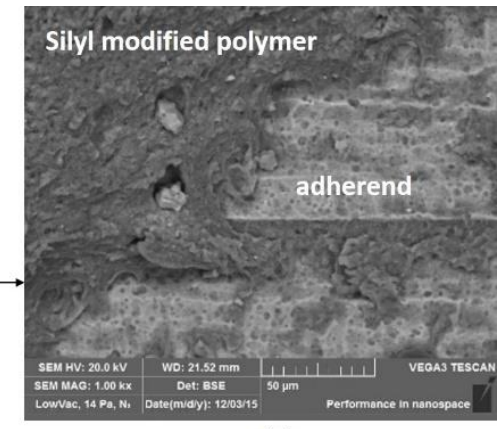

(c)
Figure 10 Fracture surface of 100\%SMP joints; (a) complete view, (b) macro view, (c) micro view

Failure fracture surfaces were investigated to justify the type of failure mode of joint. Failure mode has been used to explain the mechanism of failure and strength improvement of mixed adhesive joints. The image of fracture surfaces can be seen in Figure 6, Figure 7, Figure 8, Figure 9, and Figure 10 for all mixed adhesive compositions. The fracture surface of adhesive joint with $100 \%$ EP (Figure 6) is full adhesive failure mode. It is a failure where adhesive adheres on one of the adherend surfaces. It shows that $100 \%$ EP is the strength adhesive which can resist the shear force well, but its adhesiveness to an adherend is weak. The presence of few SMP (25\%) in EP adhesive increased the adhesiveness of mixed adhesive to an adherend without decreasing the strength of EP adhesive. Mixing of adhesiveness of SMP and strength of EP adhesive controlled the improvement of the mixed adhesive joint. Consequently, the joint strength of the mixed adhesive between EP and a few SMP increased. The fracture surface was mixed failure mode between adhesive and cohesive failure (Figure 7). The addition of much SMP (more than 50\%) in EP adhesive decreased the adhesive joint strength. Although the adhesiveness increased as increasing of SMP content, the bulk mixed adhesive became weak. The fracture surface showed the mixture between adhesive and cohesive failure mode as seen in Figure 8 and Figure 9. Contrary to $100 \%$ EP adhesive joints, $100 \%$ SMP adhesive joints had the lowest strength, but its ductility was the highest. It was appropriate to the nature of SMP adhesive where it was weak and ductile adhesive. Its adhesiveness is very high, but its strength is very low.

\subsection{CONCLUSION}

Mixed adhesive single lap joints of etched aluminum have been evaluated. The study has shown that the chemical treatment on the aluminum surface can dissolve the natural oxide layer, clean and activate the aluminum surface, and generate a new porous of the oxide layer on the aluminum surface. The presence of few SMP (up to 25\%) in epoxy adhesive increased joint strength due to increasing the adhesiveness without decreasing the strength of bulk mixed adhesive. In this composition, the fracture surface was mixed between adhesion and cohesion failure mode. The addition of much SMP in EP adhesive decreased the adhesive joint strength because of weakening the bulk mixed adhesive although the adhesiveness increased.

\section{Acknowledgement}

The authors gratefully acknowledge the financial support provided by Sebelas Maret University through MRG Research Grant 2016.

\section{References}

[1] da Silva, L. F. M., Ferreira, N. M. A. J., Richter-Trummer, V., and Marques E. A. S. 2010. Effect of Grooves on the Strength of Adhesively Bonded Joints. International Journal of Adhesion \& Adhesives. 30: 735-743. DOI: https://doi.org/10.1016/j.jjadhadh.2010.07.005.

[2] Arenas, J. M., Alía, C., Narbón, J. J., Ocaña, R., and Gonzalez, C. 2013. Considerations for the Industrials Applications of Structural Adhesive Joints in the Aluminum-composite Material Bonding. Composite: Part B. 44: 417-423.

DOI: https://doi.org/10.1016/j.compositesb.2012.04.026.

[3] Banea, M. D. and da Silva, L. F. M. 2009. Adhesively Bonded Joints in Composite Materials: An Overview. Proceedings of the Institution of Mechanical and Applications Engineers, Part L: Journal of Materials Design. 223(1). DOI: DOI: 10.1243/14644207JMDA219.

[4] Vietri, U., Guadagno L., Raimondo M., Vertuccio L., and Lafdi K. 2014. Nanofilled Epoxy Adhesive for Structural Aeronautic Materials. Journal composites: Part B. 61: 73-83. 
DOI: https://doi.org/10.1016/j.compositesb.2014.01.032.

[5] Pereira, A. M., Ferreira, J. M., Antunesdan, F. V., and Bartolo P. J. 2010. Analysis of Manufacturing Parameters on the Shear Strength of Aluminum Adhesive Single-lap Joints. Journal of Materials Processing Technology. 210: 610-617. DOI: https://doi.org/10.1016/j.jmatprotec.2009.11.006

[6] Zhou, Y. Pervin, F. Lewis, L. and Jeelani, S. 2007. Experimental Study on the Thermal and Mechanical Properties of Multi Walled Carbon Nanotube-Reinforced Epoxy. Materials Science and Engineering: A. 452-453(0): 657-664.

DOI: https://doi.org/10.1016/j.msea.2006.11.066.

[7] Norhakim, N. Ahmad, S. H J., Chia C.H. and Huang, N. M. 2014. Mechanical and Thermal Properties of Graphene Oxide Filled Epoxy Nanocomposite. Journal Sains Malaysia. 43(4): 603-609.

[8] Bouchikhi, A. S. Megueni, A. Gouasmi, S. Boukoulda, F. B. 2013. Effect of Mixed Adhesive Joints and Tapered Plate on Stresses in Retrofitted Beams Bonded with A Fiber-reinforced Polymer Plate. International Journal Materials and Design. 50: 893-904.

DOI: https://doi.org/10.1016/j.matdes.2013.03.052.

[9] Diharjo, K., Firdaus, Y., Raharjo, W. W., and Tjahjana, D. P. T. 2014. Improvement of Strength on Joint of GFRP/Al-5083 Joint Using Epoxy/Al-Powder Adhesive for Electric Vehicle Car Body. 2014 IEEE International Conference on Electrical Engineering and Computer Science.

DOI: 10.1109/ICEECS.2014.7045244.

[10] Kahraman, R. Sunar, M. and Yilbas, B. 2008. Influence of Adhesive Thickness and Filler Content on The Mechanical Performance of Aluminium Single-Lap Joints Bonded with Aluminium Powder Filled Epoxy Adhesive. Journal of Materials Processing Technology. 205(1-3): 183-189. DOI: https://doi.org/10.1016/j.jmatprotec.2007.11.121

[11] Pereira, A. M. Reis, P.N.B. Ferreira, J. A. M. and Antunes, F. V. 2013. Effect of Saline Environment on Mechanical Properties of Adhesive Joints. International Journal of Adhesion \& Adhesives, 47: 99-104. DOI: https://doi.org/10.1016/j.ijadhadh.2013.08.002.

[12] da Silva L. F. M and Lopes, M. J. C. Q. 2009. Joint Strength Optimization by the Mixed-adhesive Technique. International Journal of Adhesion \& Adhesives. 29: 509-514. DOI: https://doi.org/10.1016/j.jjadhadh.2008.09.009L.

[13] Marques, E. A. S. da Silva, L. F. M. Flaviani, M. 2015. Testing and Simulation of Mixed Adhesive Joints for Aerospace Applications. International Journal Composites: Part B. 74: 123-130.

DOI: https://doi.org/10.1016/j.compositesb.2015.01.005.

[14] Kim, Y. J., LaBere, J., and Yoshitake, I. 2013. Hybrid epoxy-silyl Modified Polymer Adhesives for CFRP Sheets Bonded to a Steel Substrate. Journal Composites: Part B. 51: 233-245.
DOI: https://doi.org/10.1016/j.compositesb.2013.03.026.

[15] Banea, M. D. and da Silva, L. F. M. 2009. Adhesively Bonded Joints in Composite Materials: An Overview. Proceedings of the Institution of Mechanical and Applications Engineers, Part L: Journal of Materials Design. 223(1). DOI: DOI: 10.1243/14644207JMDA219.

[16] R. Trethewey Kenneth. 1988. Corrosion. Longman Group. UK Limited.

[17] Lonardo, P. M., and Bruzzone, A. A. G. 1989. Influence of Surface Roughness Parameters on the Mechanical Strength In Metal Gluing. CIRP Ann Manuf Technol. 38(1): 571-574. DOI: https://doi.org/10.1016/S0007-8506(07)62771-1.

[18] Sahid, M., and Hashim, S. A. 2002. Effect of Surface Roughness on the Strength of Cleavage Joints. International Journal of Adhesion \& Adhesives. 22(3): 235-244. DOI: https://doi.org/10.1016/S0143-7496(01)00059-8.

[19] Benard, Q., Fois, M., and Grisel, M. 2005. Peel Ply Surface Treatment for Composite Assemblies: Chemistry and Morphology Effects. Composite A. 36(11): 1562-1568. DOl: https://doi.org/10.1016/j.compositesa.2005.02.012.

[20] Budhe, S., Ghumatkar, A., Birajdar N., and Banea, M. D. 2015. Effect of Surface Roughness Using Different Adherend Materials on the Adhesive Bond Strength. Applied Adhesion Science. 3: 20. DOI: 10.1 186/s40563-015-0050-4

[21] Khan, M. H. and Gali, O. A. A. 2016. Edrisy and A. R. Riahi, Effect of Oxidation And Surface Roughness On The Shear Strength Of Single-lap-joint Adhesively Bonded Metal Specimens by Tension Loading. Applied Adhesion Science. 4: 21. DOI: 10.1186/s40563-016-0077-1.

[22] Prolongo, S. G., and Ureña, A. 2009. Effect of Surface PreTreatment on the Adhesive Strength of Epoxy-aluminum Joints. International Journal of Adhesion \& Adhesives. 29: 2331. DOI: https://doi.org/10.1016/j.ijadhadh.2008.01.001.

[23] L. zhai, G. Ling, J. Li and Wang, Y. 2006. The Effect of Nano Particles on the Adhesion of Epoxy Adhesive. Materials Letters. 60: 3031-3033. DOI: https://doi.org/10.1016/j.matlet.2006.02.038.

[24] Baldan, A. 2012. Adhesion Phenomena in Bonded Joint. International Journal of Adhesion \& Adhesives. 38: 95-116. DOI: https://doi.org/10.1016/j.jjadhadh.2012.04.007.

[25] Barbora N., Barbora K., Pavel L., Jiř́ Š. 2015. Determination of Adhesion of Silyl Modified Polymer Adhesives to Wooden Façade Cladding-Case Study. Procedia Engineering. 108: 410-418. DOI: https://doi.org/10.1016/j.proeng.2015.06.165.

[26] Prolongo, S. G., Gude, M. R., and Ureña, A. 2010. Nanoreinforced Adhesives, Nanofibers, Ashok Kumar (Ed.). InTech. DOI: 10.5772/8147. 